\title{
An Ethics of Recognition in Global and Teacher Education: Looking through Queer and Postcolonial Lenses
}

\author{
Steven Camicia
}

Utah State University, USA

\begin{abstract}
Global education and teacher education struggle to address a wide range of objectives surrounding curriculum. Some of these objectives are market-driven while others emphasise critical democracy. A theoretical framework is presented that combines literature from queer theory and postcolonial theory to better understand curriculum through a poststructural ethics of recognition. Recognising individuals and groups beyond normalising discourses and creating third spaces are the main themes of this ethics in curriculum work and global teacher education. These interpretations are illustrated with a brief example of a teacher education project that encouraged dialogue about global inequities and colonisation between pre-service teachers in the Philippines and the United States.
\end{abstract}

Keywords: Global education, democratic education, postcolonial theory, queer theory, ethics, social justice

\section{Introduction}

The objectives of global education vary widely. While some intend the curriculum to serve the interests of a national community, others would like global education to serve the interests of a global community (Parker and Camicia, 2009). In addition, while some intend global education to strengthen the possibilities of emancipatory democracy, others intend for global education to strengthen markets (Camicia and Franklin, 2010; Fine and Weis, 2003). Beyond these binary constructions, the objectives of global education are a complex mix of these objectives and others. It is within this global milieu that I propose adding complexity to our dialogues about teacher education-related global education by deconstructing oppressive categories and representations found in curriculum and society.

In this article, I use the lenses of queer and postcolonial theories to better understand ways that teacher education in the area of global education can create curriculum and instruction that promotes emancipatory, democratic, global com- 
munities. In particular, I offer a poststructural lens of recognition as a way to facilitate communication that promotes third spaces in teacher education and curriculum. Finally, I use these lenses to examine the case of a current curriculum project between pre-service teachers in a colonising nation, the United States, and pre-service teachers in a colonised nation, the Philippines. I conclude that a socially just global education curriculum is possible when a third space is established. A third space encourages dialogue with an eye toward questioning and deconstructing oppressive boundaries and categories. Queer theory and postcolonial theory provide a basis for supporting dialogue that encourages third spaces.

\section{Lenses of Recognition}

What ways might postcolonial and queer theories be productively interwoven or tangled? There are doubtless many ways, but in this article, I present one way in an attempt to open dialogue that address injustices such as colonisation and heterosexism. The way that I interweave or tangle these theories is through understanding how representation and misrepresentation are related to recognition and misrecognition. Representation and recognition are conceptually linked because the way that bodies are represented has an impact upon the way that these bodies are or are not recognised. While postcolonial theory often focuses upon representation and misrepresentation, queer theory often focuses upon recognition and misrecognition. An indication of the weaving and tangling of the two theoretical orientations is illustrated in the way that representation and recognition are components of each orientation. In this section, I first examine the concept and action of recognition. I then show how representation and recognition are woven and tangled by processes of normalisation. These processes serve as a function of power within curriculum.

Recognition can be an ethical component of many queer and postcolonial theories. There are many interpretations of the concept of recognition. The etymology of recognition is tied to recognisance, a legal record of obligation. In this sense, an individual is bound by an obligation to the state. Among some of the popular usages, recognition can mean formally giving praise for an accomplishment such as earning a scholarly degree. The usage that queer theorists often use relates to literally recognising individuals or groups in the way that they understand themselves and the world. Closely tied to this meaning is an interpretation of the concept of recognition as creating third spaces or safe spaces for marginalised voices in contexts where these voices are usually silenced (Fine and Weis, 2003). Recognition in this instance could involve, for example, placing the assumptions of a dominant culture under examination while privileging the voices of marginalised voices. In this article, I will focus upon this interpretation of recognition, recognising and creating third spaces. 
Recognising can occur in a third space and a third space can occur in recognising because both are bound by a nurturing of possibilities, voices, and perspectives that are usually drowned out by normalising and dominant discourses. In a third space, categories that serve to divide and subjugate people are deconstructed so that new understandings and recognising can occur. These interpretations align well with a queer and postcolonial ethic of recognition in ways that open possibilities for learning social justice in global education and teacher education programs. In what follows, I first interpret these ways of understanding recognition as it relates to an ethics of recognition.

\section{Recognising}

One of the powerful functions of 'normalising' discourses is to render beings that do not fit into dominant cultural formations as incomprehensible and unrecognisable (Butler, 2006, 2009). My blending of queer theory and postcolonial theory is an attempt to queer conversations about global education. While queer theory is interpreted by many as used exclusively within the domain of the study of gender identities, sexual orientations, and desires, queer theory provides a theoretical lens or tool for understanding how the process of normalisation works within a variety of fields. Within global education, combined with a postcolonial lens, we can better understand how normalising discourses work against recognition and reify oppressive power structures within schools and society.

Using examples from gendered and sexed bodies, queer theory shows implications of how bodies are inscribed by multiple and fluid cultural formations that are often oppressive. Queer theorists have interpreted the ways that non-dominant gender identities and sexual orientations are rendered unrecognisable, and those who live non-dominant gender identities and sexual orientations are represented or regarded as abnormal or not fully human. As it relates to the illustration that I give later in this article, Americans (mainly, White males) colonised the Philippines and established a heterosexist, Eurocentric, patriarchal system of education, which represented hetero, European/American, patriarchy as the measure or norm in which the entire globe was to be measured. Not only were the Filipina and Filipino people not recognised, they were misrecognised and misrepresented within the education system forced upon them by Americans. A queering of postcolonial theory increases the possibilities of understanding this process of dehumanisation by combining multiple perspectives of how the processes of normalisation and representation are linked.

Foucault's $(1990,1995,2003)$ examinations of discourses related to 'normalisation' inform the ways that we might approach an ethics of recognition. For example, the fields of psychiatry and law formed discourses that defined 'normal' and 'abnormal' thought and behaviour. These normalising discourses also function to regulate bodies with the stated goal of 'curing the individual of abnormality'. This can be seen 
later in my example from the exchanges between students in the Philippines and United States where English is represented as the norm in the curriculum of both countries. This inscription of English upon the bodies of students in the Philippines by the imposition of an American education system misrepresents Filipinas and Filipinos as 'deficient' and 'abnormal' if they do not manifest English in their thoughts and language. The raison d'être of the Western disciplines of psychiatry and law were to define and identify 'abnormal' individuals in order to discipline them into thinking and behaving normally. Foucault illustrated the ways that what is considered within the 'norm' is highly contextual and reflects the linkage of knowledge/power. Because knowledge is contextual, dominant cultural assumptions about what is considered 'normal' reflects these dominant assumptions. As a result, those who do not fit within dominant assumptions about the world are systematically unrecognised, marginalised, and oppressed. An ethics of recognition seeks to disrupt dominant assumptions concerning what is normal by recognising people for how they understand themselves and the world, rather being compared with a norm.

Butler (2006) and other poststructural philosophers have cited the work of Levinas related to an ethics of recognition, which is grounded in Levinas's (1981) concept of the face. Levinas writes:

A face as a trace, trace of itself, trace expelled in a trace, does not signify noema, but an invitation to the fine risk of approach qua approach, to the exposure of one to the other, to the exposure of this exposedness, the expression of exposure, saying. In the approach of a face the flesh becomes word, the caress a saying. The thematisation of a face undoes the face and undoes the approach. The mode in which a face indicates its own absence in my responsibility requires a description that can be formed only in ethical language. (Levinas, 1981:94)

The face is that in a being that is not signifiable. My struggle with another involves my inability to signify that which is beyond signification. It is a 'trace expelled in a trace.' Although I cannot define or signify another, according to Levinas (1981) and Butler (2006), an ethical way to approach another is to realise my inability to signify, categorise, define, or name. These are one of the functions of discourses of normalisation. Butler writes, 'politics-and power-work in part through regulating what can appear, what can be heard' (Butler, 2006:147). An ethics of recognition would deconstruct categories and multiply possibilities while acknowledging that interpretation is provisional, constantly inviting new possibilities.

\section{Creating Third Spaces}

Creating possibilities in educational spaces for recognising to occur has been described by some as third spaces. Soja (2009) writes that third spaces resist definition but can be thought of as 'an invitation to enter a space of extraordinary openness, a place of critical exchange where geographical imagination can be expanded to encompass a multiplicity of perspectives that have heretofore been considered by the epistemological referees to be incompatible, uncombinable' (Soja:51). It can be

28 International Journal of Development Education and Global Learning 4(1) 2012 
a place where normalising discourses are weakened and where unrecognisable, impossible, and 'abnormal' voices are privileged.

Postcolonial theorists illustrate how mis/representation has been a common tool used by colonisers to oppress those colonised (Bhabha, 2003; Said, 1979; Spivak, 1999). Bhabha presents a way to connect an ethics of recognition to the possibility of a third space where dominant, normalising discourses are weakened through narrative. When marginalised groups and individuals have spaces to narrate, new possibilities emerge that challenge the discourses that make people unrecognisable. The 'right to narrative' is central to Bhabha's conception of human rights. He writes,

To protect the 'right to narrate' is to protect a range of democratic imperatives: it assumes that there is an equitable access to those institutions-schools, universities, museums, libraries, theatres-that give you a sense of a collective history and the means to turn those materials into a narrative of your own. Such an assured, empowered sense of 'selfhood', the knowledge that to tell your story is to know that there is a 'public culture' in which it will be heard and could be acted upon, depends upon the nation's guardianship of what Article 5 of the International Convention on Economic, Social and Political Rights defines as 'the right to take part in cultural life'. (Bhabha, 2003:180-181)

In teacher education and curriculum, the right to narrate forms the possibility of a third space. This could be a space where teachers and students question mis/representations and normalising discourses that have served to drown out narratives that question systems of domination and subjugation. This could come close to Bhabha's (2009) description of the third space as a 'challenge to the limits of the self in the act of reaching out to what is liminal in the historic experience, and in the cultural representation, of other peoples, times, languages, texts' (Bhabha, 2009: xiii).

Fine, Weis, Centrie, and Roberts (2000) describe what this third space might look like in schools as a curriculum where students and teachers enter:

interrogation into the borders of the space, trying to discern what defines, marks, separates and joins this space to surrounding structures and social formations; investigation into the interior relations within the space, relations of hierarchy, justice, reciprocity, trust, and conflict; analyses of individual and group identity construction, deconstruction, and reconstruction for youth and adults within the space; and research into the activist joints of this space with other such spaces, counter-hegemonic ideologies, and social movements. (Fine, Weis, Centrie, and Roberts, 2000: 133)

Borders are cultural formations on a constantly shifting landscape that is a central part of the curriculum. Representation and recognition can be central components of this landscape as students and teachers become activists in a struggle to problematise borders with an objective of social justice. In teacher education programs, students and teachers in this context would embrace complexity. Andreotti (2010) describes it as a place 'where students become 'border crossers' and 'edge walkers' 
who can translate learning and information from one community into another and who are open to learn/negotiate meaning with people who are different from them, in unfamiliar contexts' (Andreotti, 2010:18-19).

Third spaces are filled with contradictions and complexity as boundaries that have been defined within the realm of normality are questioned. It is a place and process of deconstruction and construction, and as a result, new boundaries always represent a new norm that can serve to oppress. In the context of this theoretical framework of recognition and third space, I next present an example that helped me develop my understandings of what this might and could look like. While the following example is brief, it serves as a basis for reflection and possibilities in global education and teacher education through queer and postcolonial lenses.

\section{Dialogue between Pre-service Teachers in the Philippines and United States}

I offer an illustration of one of the projects that Dr. Alfredo Bayon, Southern Leyte State University (SLSU), Philippines, and I have been collaborating on. For a more detailed description of our project see Camicia and Bayon, in press. Dr. Bayon is Filipino and has been a professor of social studies education in the SLSU teacher education program for about 15 years. I am a White, queer, male and have been an assistant professor of social studies education in the Utah State University (USU) teacher education program for about five years. Our universities have a memorandum of understanding where we plan on facilitating exchanges of pre-service teachers at both universities and work on projects such as the one that I will briefly detail here.

Our project involved an online discussion board between 16 pre-service teachers in each country. Students formed discussion groups of between three and four students where they spoke of global issues, which I describe later in this section. Dr. Bayon and I had hoped that the dialogue between our students would occur twice a month for two months. Unfortunately, student posts to the discussion board occurred in about half of the occurrences we hoped for, due to a lack of access to technology in the Philippines. Although limited in the amount of data that we collected, the project provided a basis for reflection and ways to think about similar projects and objectives in the future.

Before starting our project, we were suspicious of my intents as a White male from the United States. To add further complexity to this project, my history as a queer male made me aware of the fluidity of borders and boundaries enough to believe that a queer postcolonial dialogue could be possible. I conclude this section with reflections on the ways that my queer identity helped me recognise possibilities in global education for the interweaving and tangling of queer and postcolonial theories. 
Dr. Bayon and I were concerned that our collaboration and project should not turn into another example of a White male from the United States colonising the Philippines with 'truth'. My positionality as a male is closely tied to the patriarchal aspects of colonisation. Male privilege makes it difficult for me to see or understand some of the most oppressive and insidious aspects of patriarchy within the United States, and this ignorance that is tied to male privilege is only intensified when dialoguing with those who have been oppressed through colonisation. Colonial maleness is tied to a complex history where the all norms of value are closely tied to the epistemology of European males. These epistemologies are very closely tied to tools such as hierarchical structures in all social relations that hold European/American males as the norm by which the entire globe is measured. These hierarchical structures are embedded in the curriculum of the Philippines and the United States, as White male bodies are portrayed in the history books as the central means of 'progress'. This is also communicated through the portrayal and centrality of male dominated fields of science. It is also communicated through the abundant examples of male violence throughout history, representations of male bodies as abnormal if this violence isn't close at hand.

One of the ways that we addressed our concerns related to my identity as coloniser and Dr. Bayon's identity as colonised was to be explicit about the intents of our project, as well as the historical and contemporary context of oppression in which the project was performed. We intended that the project deconstruct categories and binaries constructed by the United States that have functioned to oppress the Philippines. Historically, the United States created and has maintained normalising discourses where the United States is portrayed as the 'beacon on a hill' or a norm that all nations should follow. This has been illustrated often in the textbooks and curriculum in the Philippines by using non-culturally responsive examples from the United States. For example, in addition to the use of English as an official language of instruction, examples from stories of American 'heroes' are prevalent.

Dr. Bayon and I began dialogue about the ways that the United States represented the Philippines throughout its colonisation of the Philippines. These representations were perennially demeaning to Philippine people and culture while holding the United States people and culture as the paradigm of 'democracy' and 'progress'. The curriculum in the Philippines places the education system in the United States as superior by using the scope and sequence of the United States along with similar content that does not recognise Filipino culture. The scope and sequence of the curriculum in the Philippines mirrored the scope and sequence of the curriculum in the United States when the United States used public education in the Philippines as a means for colonisation over 100 years ago. The scope and sequence is currently very similar to that of the United States, and English is still one of two national languages of instruction. 
Dr. Bayon and I hoped that our discussion board project around the complexity of colonisation might serve as a third space for discussion between pre-service teachers at SLSU and USU. We thought that one possibility for creating a curriculum aligned with our objectives would be for students to post discussions related to topics of colonisation and anti-colonisation. Specifically, before posting to the board, students read about the role of English as a tool that the United States used to colonise the Philippines. SLSU and USU students read articles by Filipino authors concerning the topic of English as a language of instruction. In addition, students read editorials from newspapers in the Philippines that spoke of a controversial education policy that made it mandatory that schools use regional languages in the curriculum. Before implementation of the policy, most of the languages in the Philippines were excluded from the curriculum. Some editorials spoke of the necessity of speaking English to become competitive in a global economy. Other articles disagreed, speaking of the cultural and educational benefits of providing instruction in the regional languages of the students. Based upon the readings, SLSU and USU students were able to start discussions about the role of the United States in colonising the Philippines and the lasting oppression that results from this colonisation. Although none of the students discussed English language explicitly, the articles created an opening where colonisation and history could be discussed. The following are posts to the discussion board:

Filipina: I would like U.S. students to be aware of the 'not-so-good' relationship between the Filipinos and the Americans before as the latter were once one of our colonisers. Later on however, when the Japanese invaded our country and brought terror, the Americans were on our side against the mighty forces of Japan. Until present, these two countries remain in good terms.

American: When history is presented in a cut and paste fashion where only one side is shown, the U.S. is in the right $98 \%$ of the time. At least that is how it is in the United States. I'm sure in most countries it is the same with the people in charge being able to do no wrong and the 'bad' guy is always on the opposing force. The children always get to hear of the atrocities caused by the other side but hardly ever hear of the bad choices that the U.S. has made in conjunction with those 'bad people.' With a more rounded version of events everyone can get a much more accurate view of the world and the past as a whole, not just the sunny, we are awesome version that likes to be told.

American: I'm really interested in hearing about American history from your point of view. I know that in my schools, when I learned about the different wars and the terrorist attacks, America was always the good guy. Like the article [(Kumashiro, 2003)] said, we always learned that the United States saved the world. I want to know how other countries see the US history.

Students were able to use the readings as a basis for examining the role of representation within the process of colonisation. In this instance, the function of historical representations is a topic for creating a space that questions American exceptionality as it is contained in the history curriculum. A discourse of American exceptionality serves to marginalise the Philippines and empower the United States as a coloniser. A dialogue about these representations and history helped open a 
third space where dialogue could produce new possibilities to deconstruct the borders and categories that serve to marginalise.

Students at both universities were positive about the possibilities of the dialogue project. The following discussion board postings indicate these possibilities:

Filipino: Such dialogue between these two institutions helps promote a congenial atmosphere among them. Such atmosphere promotes greater chances to communicate, which will eventually allow the exchange of ideas between them with respect to their historical backgrounds and of their curriculum.

American: I think that it will open doors to different viewpoints about the world. Too often a person's views are trapped by what is around them and they do not bother to look outside of themselves to find a different answer, even if it isn't one that they want. By participating in this dialogue I hope to get out of my Utah mindset and become a more worldly and effective person.

In addition, students discussed issues related to gender norms. For example, the following are discussion board postings related to the empowerment of women:

Filipina: Women in the Philippines, before, were just shadows of men. Parents tended not to send their daughters to school because they would just end up being housewives. They thought 'what's the use of the diploma you earned when you are just going to end up as a housewife?' Things have changed now. Women are taught that we are equal to men. We can be bosses too not just being bossed around. Do you think United States will have a woman president? Just a thought....

American: I really think that in current social studies curriculum, women are being empowered. Girls are being taught that they can do anything a man can do, that we all have the same rights.

In the above posts, the Filipina student questions the discourse of American exceptionality by asking, 'Do you think the United States will have a woman president?' This is a reference to the fact that in the Philippines, women have already served as national presidents and the United States has not. The American student raises the topic of gender equity and the possibilities of curriculum to work towards social justice. Although the discussion board was short lived, there appeared a willingness to enter into a third space where norms and boundaries related to history, gender, and identity are deconstructed with an eye toward social justice.

Dr. Bayon and I did not expect the discussion board to include a discussion of gender norms and inequities, but we hope to include issues of gender identity and sexual orientation to the discussion board in the future. As a queer male, I become aware of new possibilities to blur the sexual orientation and gender identity boundaries that have caused suffering in my life and the lives of others. I found conversations about sexual orientation and gender identity in the Philippines to disrupt the misrepresentation that has marginalised Filipinos and Filipinas by placing the United States as the norm to aspire to. It disrupted discourses of American exceptionality by questioning the progressiveness of the United States in the inclusion of sexual minorities who are on the margins.

I was first struck by this possibility of dialogues about queer issues between student in the Philippines and the United States when I noticed three restrooms at a 
restaurant in the Philippines. One restroom door had the silhouette of a figure with a flower on her hair. Another restroom door had a silhouette of a figure with a top hat. Between the two restrooms, there was a restroom that had a silhouette with an individual with a flower on a top hat to indicate a place for individuals that don't associate with binary constructions of gender. This is tied to an ethics of recognition that I hope to develop more in future dialogue projects by placing sexual orientation and gender identity as discussion topics that can create third spaces with multiple opportunities to deconstruct oppressive colonial and heteronormative boundaries.

\section{Conclusion}

In this article, I have presented a theoretical framework for understanding ways to address social justice issues such as colonisation, gender inequalities, and heteronormativity within our teacher education programs and global education curriculum. My interpretation of an ethic of recognition is also wrapped within the realisation that any such account is necessarily incomplete. But the impossibility of creating a new 'truth' does not diminish the need to struggle and connect with the intent of creating alliances across differences toward emancipatory third spaces. The SLSU and USU dialogue was an attempt to create a third space where students could begin to recognise differences and address complexity. This illustration was brief due to material constraints of the project and is not meant to be held up as another 'truth'. The project is an illustration of possibilities for future collaborations and dialogues about ways that we might support work in third spaces.

One of the interpretations that we made about the project was the incredible complexity of the project. This complexity was in large part contained in the objectives and formation of the project between two professors with different positionalities. Although that data that I have presented is limited by the brief interactions of students, the process of developing the curriculum can open conversations about the possibility of creating third spaces through attention to an ethics of recognition where boundaries are examined and oppressive categories are deconstructed.

The aspect of representation and communication as always contingent and incomplete was ever present in our project. The layers of contradiction faced us at every turn as they do in my writing of this article. These contradictions seem to almost define third spaces and an ethics of recognition because recognition, as Butler (2006) and Levinas (1981) point out, is always incomplete. As soon as it is complete, it becomes a 'truth' that can serve a normalising discourse that oppresses rather than emancipates. The SLSU and USU project serves as an illustration of this complexity, contingency, and incompleteness.

Finally, I refer to Todd (2008) who cautions against insisting 'that cherished principles can be transferred to 'impressionable' youth.' Instead, she advocates education as 'processes of negotiation and translation that youth employ in their engagement with rights, democracy, and citizenship' (p.155). This resonates with my 
understanding of a third space in education as a place devoted to an ethics of recognition. This is a place where oppressive categorisations and norms are deconstructed to recognise individuals for who they are while dismantling the structures that serve to marginalise, structures such as colonisation and heteronormativity. This is the space where queer and postcolonial theory can interweave and tangle toward an emancipatory global education curriculum in teacher education.

Steven Camicia is an Assistant Professor at Utah State University. He researches curriculum and instruction in the areas of perspective consciousness, postcolonial theory, queer theory, global education, and social justice as they relate to democratic decision making processes.steven.camicia@usu.edu

\section{References}

Andreotti, V. (2010) Global Education in the '21st Century': Two different perspectives on the 'post-' of postmodernism. International Journal of Development Education and Global Learning, 2(2), 5-22.

Bhabha, H. K. (2003) On writing rights Globalizing rights: The Oxford Amnesty lectures 1999 (pp.162-183): Oxford University Press, USA

Bhabha, H. K. (2009) In the cave of making: Thoughts on third space. In K. Ikas and G. Wagner (Eds.), Communicating in the third space. New York: Routledge.

Butler, J. (2006) Precarious life: The powers of mourning and violence. New York: Verso.

Butler, J. (2009) Frames of war: When is live grievable? NY: Verso.

Camicia, S. P., and Bayon, A. (in press) Democratic education curriculum development between the colonizer and the colonized: Complexities, contradictions, obstacles, and possibilities of global alliances. In T. C. Mason and R. J. Helfenbein (Eds.), Ethics and international curriculum work: The challenges of culture and context.

Camicia, S. P., and Franklin, B. (2010) Curriculum reform in a globalised world: The discourses of cosmopolitanism and community. London Review of Education, 8(2), 93-104.

Fine, M., and Weis, L. (2003) Silenced voices and extraordinary conversation: re-imagining schools. New York: Teachers College, Columbia University.

Fine, M., Weis, L., Centrie, C., and Roberts, R. (2000) Educating beyond the borders of schooling. Anthropology and Education Quarterly, 31(2), 131-151.

Foucault, M. (1990) The history of sexuality: Volume I: An introduction (R. Hurley, Trans.). New York: Vintage Books. Foucault, M. (1995) Discipline and punishment: The birth of the prison (A. Sheridan, Trans.). New York: Vintage Books.

Foucault, M. (2003) Abnormal: Lectures at the Collège de France, 1974-1975.

Kumashiro, K. K. (2003) 'Posts' perspectives on anti-oppressive education in social studies, English, mathematics, and science classrooms. Educational Researcher, 30(3), 3-12.

Levinas, E. (1981) Otherwise than being or beyond essence (A. Lingis, Trans.). Boston: Martinus Nijhoff Publishers.

Parker, W. C., and Camicia, S. P. (2009) Cognitive praxis in today's 'international education' movement: Intents and affinities. Theory and Research in Social Education, 37(1), 42-74.

Said, E. W. (1979) Orientalism (1st Vintage Books ed.). New York: Vintage Books.

Soja, E. W. (2009) Toward a new consciousness of space and spatiality. In K. Ikas and G. Wagner (Eds.), Communicating in the third space. New York: Routledge.

Spivak, G. C. (1999) A critique of postcolonial reason: Toward a history of the vanishing present. Cambridge, MA: Harvard University Press.

Todd, S. (2008) Toward an imperfect education: Facing humanity, rethinking cosmopolitanism. Boulder, CO: Paradigm Publishers. 